\title{
EDUCAÇÃO DE ORIENTADORAS E DE JOVENS EM CONFLITO COM A LEI EM UM PROGRAMA DE MEDIDAS SOCIOEDUCATIVAS ${ }^{*}$
}

\author{
EDUCATION OF GUIDANCE AND YOUNG PEOPLE IN CONFLICT WITH THE LAW IN A \\ PROGRAM OF MEASURES SOCIOEDUCATIONAL
}

Rubia Fernanda Quinelatto Caparrós
Doutoranda em Educação - UFSCar | Brasil
E-mail: rubiafq@hotmail.com

Elenice Maria Cammarosano Onofre Doutora em Educação - UFSCar | Brasil E-mail: linocam@uol.com.br

REVISTA PEDAGÓGICA

Revista do Programa de Pós-graduação em Educação da Unochapecó | ISSN 1984-1566 Universidade Comunitária da Região de Chapecó | Chapecó-SC, Brasil Como referenciar este artigo: CAPARRÓS, R. F. Q. ONOFRE, E. M. C. Educação de orientadoras e de jovens em conflito com a lei em um programa de medidas socioeducativas. Revista Pedagógica, Chapecó, v.15, n.31, p. 149-164, jul./dez. 2013.

RESUMO: O presente artigo é resultado de pesquisa do Mestrado em Educação, da Universidade Federal de São Carlos, tendo como principal objetivo identificar compreensões sobre processos educativos de orientadoras de um Programa de Medidas Socioeducativas, no município de São Carlos/SP, com jovens autores(as) de ato infracional. A pesquisa de natureza qualitativa contou com a participação de seis orientadoras e foram utilizados como procedimentos metodológicos entrevistas, registros em diários de campo e análise documental. Os dados coletados foram organizados e deles emergiu, como um dos focos de análise, como se educam as orientadoras com os(as) jovens em conflito com a lei em um Programa de Medidas Socioeducativas. A análise dos dados está embasada em autores latino-americanos como Freire, Fiori e Dussel, bem como em pesquisadores(as) do tema, que subsidiaram as reflexões desvelando e construindo caminhos em práticas sociais que ocorrem no interior de espaços de restrição de liberdade. Resultados da investigação evidenciam o educar e educar-se das orientadoras com os(as) jovens em conflito com a lei, constituindo em referências para pesquisas na área e possibilidades de formação de profissionais que atuam em Programas de Medidas Socioeducativas..

PALAVRAS-CHAVE: Processos educativos em espaço de restrição de liberdade. Orientadoras de Medida Socioeducativa. Educação não escolar.
ABSTRACT: This article is the result of research of Masters in Education, Federal University of São Carlos, with the primary objective to identify insights into educational processes should a Programme of Measures Socio, in São Carlos / SP, with young authors (the ) an infraction. The qualitative research involved the participation of six guidelines and were used as instruments interviews, records daily and documentary analysis. The data were collected and organized them emerged as a focus of analysis: how to educate the guidelines with (the) youth in conflict with the law in a Programme of Measures Socio. Data analysis is based on Latin American authors such as Freire, Fiori and Dussel, as well as researchers (the) theme, which supported the reflections revealing and constructing paths in social practices that occur within areas of restricted freedom. Research findings show the educate and educate yourself with the guidelines (the) youth in conflict with the law, constituting references to research in the field and training opportunities for professionals working in programs Socio measures.

KEYWORDS: Educational processes in space restriction of freedom. Advisers Measuring Socio. Education without school. 


\footnotetext{
* O artigo origina-se de Dissertação de Mestrado, intitulada "Entre saberes, sabores e desafios da tarefa educativa com jovens em conflito com a lei: como as educadoras significam os processos educativos do espaço do programa de medidas socioeducativas em meio aberto", defendida junto ao PPGE - UFSCar, em 2013, financiada pela CAPES - Coordenação de Aperfeiçoamento de Pessoal de Nível Superior.

** Doutoranda em Educação. Universidade Federal de São Carlos. Programa de Pós-Graduação em Educação.

E-mail: rubiafq@hotmail.com

*** Doutora em Educação. Docente do Programa de Pós-Graduação em Educação Universidade Federal de São Carlos. E-mail: linocam@uol.com.br
}

Entre saberes, sabores e desafios da tarefa educativa com jovens em conflito com a lei: como as educadoras significam os processos educativos do espaço do programa de medidas socioeducativas em meio aberto.

\section{INTRODUÇÃO}

O presente artigo é resultado da pesquisa oriunda da Dissertação de Mestrado defendida em 2013, em que se buscou compreender de como se dá, na perspectiva das orientadoras, os processos educativos entre orientadoras e jovens em um Programa de Medidas Socioeducativas em Meio Aberto, Liberdade Assistida e Prestação de Serviços à Comunidade que atende jovens autores(as) de atos infracionais, no município de São Carlos/SP.

Dentre os muitos desafios enfrentados na pesquisa realizada, esteve o de evitar utilizar aportes teóricos advindos unicamente da cosmovisão de raiz europeia. A análise dos dados foi embasada em autores latino americanos, como Freire (1983a, 1983b, 2000), Fiori (1991) e Dussel (1995, 2001, 2005), bem como em pesquisadores(as) do tema, que subsidiaram as reflexões, no sentido de desvelar e construir caminhos em diferentes práticas sociais que ocorrem no interior de espaços de liberdade vigiada, e que anunciam a especificidade dos processos educativos que nelas ocorrem, podendo contribuir na (re)integração dos jovens em conflito com a lei. Tais autores vislumbram a educação que vai além da transmissão de conteúdos formais, visando a reflexão crítica da realidade em que estão inseridos, com o propósito de sua transformação.

Freire (1983a) sinaliza como caminho possível a tomada de consciência e a transformação do indivíduo: a Educação Libertadora. Parte do pressuposto que a Educação Libertadora propicia possibilidades e conhecimentos diversos, uma vez que a relação dialógica entre os pares permite aos sujeitos serem ativos neste processo, conhece a realidade e o indivíduo atinge um nível de ação e reflexão que podem se traduzir em mudanças em suas atitudes e escolhas.

Fiori (1991, p. 83) fortalece tal perspectiva ao afirmar que,

A educação é esforço permanente do homem para constituir-se e reconstituir-se, buscando a forma histórica na qual possa re-encontrar-se consigo mesmo, em plenitude da vida humana, que é substancialmente, comunhão social. Esse re-encontro que, no horizonte do respectivo momento histórico, coloca o homem em seu lugar próprio, tem um nome adequado: autonomia e liberdade. O movimento em direção à liberdade, assim entendida, define o sentido do processo educativo como libertação. A educação, pois, é libertadora ou não é educação. 
Nessa mesma direção, Dussel (2005) enfatiza a importância de uma teoria crítica contra-hegemônica, com práticas ativas que busquem a libertação, que incorpore a multiculturalidade nos processos educativos para a busca da identidade dos povos latino-americanos. Trata-se da superação da divisão capitalista do trabalho, da censura dos governantes, da exploração em todas as suas vertentes.

Dessa forma, surge um novo paradigma, o contra-hegemônico, que afeta a cultura imposta, acerca da ordem estabelecida, de seus conteúdos e suas transformações sociais. "[...] Las hipótesis que nos habían permitido negar la existencia de la cultura latinoamericana nos llevaban ahora al descubrimiento de una nueva visión crítica de las culturas periféricas, e inclusive de Europa misma" (Dussel, 2005, p.11).

Tomando nossa reflexão por este ângulo, pode-se afirmar que para além do sistema formal de educação, ambientes não escolares também propiciam processos de ensino e aprendizagem, e no dizer de Oliveira et al (2009, p.1), "[...] me construo enquanto pessoa no convívio com outras pessoas [...]”. Nesse sentido, as pessoas se formam a partir de todas as vivências, em diversos contextos socioculturais e as práticas sociais conduzem à criação de identidade do indivíduo, se inserem nas culturas e se concretizam nas relações. O diálogo fica evidenciado como um caminho ao processo educativo de aprendizado, confiança, respeito, que propicia sentimento de acolhimento e emancipação.

Nessa direção, Freire (2000, p. 23) afirma que toda prática educativa é libertadora, pois "[...] valoriza o exercício da vontade; da decisão, da resistência, da escolha; o papel das emoções; dos sentimentos; dos desejos; dos limites; [...] é substantivamente esperançosa e, por isso mesmo, provocadora de esperança".

Com base nos referenciais de autores envolvidos com o temário da educação não escolar, como Onofre (2007, 2009) e Oliveira et al (2009) compreende-se que por meio do diálogo e reflexão sobre o mundo, o ser humano toma consciência da sua existência, tornando-se protagonista de sua história.

Como sinaliza Onofre (2009, p.71): “[...] o diálogo, reconstrói a história e valoriza os momentos de aprendizagem [...]”. Pode-se afirmar, portanto, que as pessoas estão em constante processo de formação ao longo da vida e o diálogo faz parte desse processo sendo uma prática social relevante no Programa de Medidas Socioeducativas, uma vez que desencadeia processos educativos que visam fortalecer os(as) jovens em conflito com a lei, no cumprimento das medidas e no retorno ao convívio social.

Para tanto, um Programa de Medidas Socioeducativas deve garantir espaço para trocas, diálogos, desabafos, bem como ser acolhedor com os (as) jovens. Compreende- 
-se que muito além das oficinas oferecidas pela Instituição, o local é um espaço de reunião de pessoas que vivenciam situações semelhantes. É um encontro de sujeitos interlocutores, é uma troca que contribui "[...] por meio da aprendizagem participativa e da convivência fundamentada na valorização e no desenvolvimento do outro e de si mesmo" (Onofre, 2007, p.23).

Os resultados da pesquisa, conforme anunciado anteriormente, evidenciam propostas para (re)pensar as relações que ocorrem em ambientes de restrição de liberdade, a partir da perspectiva das orientadoras de medida e as práticas educativas programadas para jovens infratores(as).

\section{OS CAMINHOS PERCORRIDOS}

Os caminhos percorridos na construção da pesquisa, em um primeiro momento, aconteceram através da observação do contexto em que as orientadoras e jovens estão inseridos(as). Em seguida, a inserção se deu nas oficinas ofertadas aos(as) jovens e, posteriormente, nas reuniões dos profissionais e nos espaços de convivência do Programa.

Cabe enfatizar que de acordo com Oliveira (2009, p. 312), "Conviver é mais do que visitar [...] requer um envolvimento pessoal de observação, questionamento e diálogo. Somente olho no olho com o outro e, com ele convivendo, é que se pode detectar [...] e informações que nos são fornecidas sobre dada realidade".

Após a coleta dos primeiros dados, as colaboradoras foram convidadas a participarem do estudo e, mediante aceitação, foram organizados os encontros com as orientadoras. Tais encontros foram documentados por meio de gravações, com consentimento das participantes e as entrevistas foram realizadas de modo a compreender suas percepções em relação ao trabalho e ao espaço onde atuam.

Nesse sentido, os encontros com as orientadoras pautaram-se na observação cuidadosa organizada em diários de campo e na coleta dos dados através das entrevistas, para em fase posterior, analisar os dados obtidos, à luz do referencial teórico de estudiosos do tema.

Em relação à entrevista, Bosi (2003, p. 60) esclarece que "A entrevista ideal é aquela que permite a formação de laços de amizade [...]. Ela envolve responsabilidade pelo outro [...]. Da qualidade do vínculo vai depender a qualidade da entrevista”. O que se propõe é destacar nuances da pesquisa qualitativa em Educação.

Por sua vez, o diário de campo é um instrumento facilitador de registro de fatos e de registro das impressões do(a) pesquisador(a) frente a estes fatos. O procedimento de forma adequada é indispensável, uma vez que o diário é objeto de apoio à narrativa dos achados de pesquisa. 
Esta técnica, pelo seu caráter informal e amplo, pode-se tornar um instrumento fundamental para os educadores e grupos populares, pois [...] está formando e aperfeiçoando observadores e facilitando a reflexão coletiva da prática, através do confronto de informações, opiniões análises preliminares e visões de mundo. [...] Combiná-las com outras técnicas de investigação não só contribuirá, mas se fará necessário para o aprofundamento da busca de informações desde que obviamente o conjunto de técnicas criadas guardem coerência com o corpo teórico conceitual e princípios metodológicos que dão fundamento às práticas sociais em questão (Falkembach, 1987, p.21).

Em outras palavras, o diário de campo coloca-se como um instrumento que possibilita acompanhar a "[...] formação dos agentes na e com a prática, pois o fato de ser um registro diário permite visualizar a evolução dos conceitos e categorias, a clarificação progressiva de objetivos [...]" (Falkembach, 1987, p.24).

Apresenta-se a seguir, alguns trechos dos diários de campo que ilustram como a inserção ao espaço de pesquisa, a convivência e observações contribuíram na construção do campo de estudo.

Em alguns momentos pensei que o uso do gravador inibia ou podia estar inibindo as colaboradoras da pesquisa, pois antes de ligá-lo a conversa estava fluindo normalmente, bem como após a entrevista. Com a Paula notei que conversamos muito mais após a gravação do que no decorrer da mesma. Frente a esta situação pensei que seria importante realizar a entrevista sem o gravador, por exemplo, melhor coletar dados por meio da entrevista. Refleti sobre isso, porém tinha receio de entrevistar sem o gravador e perder a riqueza dos detalhes, uma vez que além da fala há outra comunicação realizada por gestos e olhares que eu, enquanto pesquisadora, também necessitava observar.

Em outro momento, na fase de revisão das entrevistas transcritas, Julia me disse que não teve problemas com o gravador, mas ficou com o receio de falar nomes ou características que pudessem identificar algum(a) jovem do Programa ou algum local do município, pois o trabalho realizado na Instituição é zeloso e ético.

Um fato que me trouxe muita satisfação foi à fase em que levei as entrevistas transcritas para as colaboradoras. Carolina e Julia me disseram que se sentiram muito respeitadas com este cuidado, pois eu não coletei dados e fui embora como se nunca estivesse estado ali, mas que retornei e, apesar de já possuir todos os termos de consentimento de pesquisa assinados, trouxe as transcrições da entrevista para solicitar, uma segunda vez, a publicação daqueles dados. 
Julia afirmou que quando chegar o momento dela (visto que está iniciando o curso de mestrado) fará da mesma forma que eu, pois gostou muito deste cuidado que tive com elas (participantes da pesquisa) (Diário de Campo, 05/04/2012).

Os procedimentos adotados procuraram garantir privacidade durante a participação das orientadoras e responsáveis pelo Programa, a preservação da identidade, garantindo-se o anonimato e a interrupção imediata do procedimento em caso de alguma participante solicitar, caso entendesse que determinada discussão poderia resultar em riscos à vida pessoal ou profissional. Nesse sentido, foram identificadas com nomes fictícios, resguardando o sigilo da identidade.

A análise documental do Itinerário Pedagógico, documento norteador das atividades que são realizadas com os(as) jovens no Programa, foi objeto de discussão com a coordenadora da Instituição, que colaborou de diversas formas, desde a chegada ao Programa. O uso deste documento complementou as informações obtidas por outras fontes internas, como o Plano Individual de Atendimento e a Interpretação de Medida.

\section{O EDUCAR E EDUCAR-SE DE ORIENTADO- RAS E OS JOVENS EM CONFLITO COM A LEI EM UM PROGRAMA DE MEDIDAS SOCIOE- DUCATIVAS}

O foco de análise que se apresenta neste artigo se refere a como as orientadoras e os jovens em conflito com a lei se educam no convívio junto ao Programa de Medidas Socioeducativas.

Os dados coletados e analisados revelam que as orientadoras promovem diálogos, por meio das atividades oferecidas, a fim de que os jovens tenham um espaço para falar e serem ouvidos. Dessa forma, significam suas percepções acerca do momento peculiar que estão vivenciando, bem como caracterizam o espaço de trocas como lugar de aprendizados, trajetórias de vidas por vezes tortuosas, e buscam auxiliar os(as) jovens em caminhos que lhes permitam ressignificar e construir seus projetos de vida.

Os depoimentos das orientadoras Letícia e Fátima evidenciam tal significado:

Você se forma e se constitui em todas as relações e em todos os lugares. E aqui é uma Instituição formada por pessoas que também se relacionam. Então, eu penso que seja por essas relações, pelo olhar, pela troca, pelo sorriso, pelo bom dia... tudo isso educa. Tem questões de música, das vivências e experiências do dia a dia e que na maioria das vezes está relacionado a questões de violência... ainda mais quando eles se conhecem, quando são do mesmo bairro (Letícia, 20/03/2012). 
Já teve caso do menino conversar e dizer pro outro "ah, deixa disso, muda sua vida!". Eles se educam pelo exemplo dos outros, colhendo informações e trocando também (Fátima, 19/03/2012).

Observa-se, pelos depoimentos das orientadoras Alice e Paula, que mesmo vivendo situações semelhantes - estar em conflito com a lei e cumprir a medida socioeducativa - cada jovem possui uma compreensão própria do significado das aprendizagens que ocorrem no Programa. E esta perspectiva, só é considerada, na medida em que se (re)conhece a voz do outro, como coautor da construção do conhecimento.

[...] a contribuição para cada um é diferente. [...] Tem adolescente que a maior contribuição é restabelecer um convívio familiar bacana, que os pais consigam exercer seus papéis e isso dá conta de que o adolescente não infracione mais (Alice, 23/03/2012).

Cada um que passa aqui é muito único. Teve um jovem aqui que me ensinou muito, ele era muito resiliente. Um caso grave, tinha uma casa que era um antigo lixão... e nele eu vi que a infração foi algo muito pontual e quando chegou aqui ele era servente de pedreiro, ajudava a família e sempre era muito grato com tudo. A resiliência de alguns adolescentes me ensina muito e me espanta muito também, porque a gente reclama de tanta coisa e aqui tem casos tão caóticos, que quando você faz as intervenções você vai provocando mudanças (Paula, 15/03/2012).

Nesta relação propiciada por diferentes atividades, orientadoras e jovens se relacionam, dialogam e trocam, por meio de processos educativos, tidos como inerentes e decorrentes das práticas sociais que vivem no Programa de Medidas Socioeducativas.

Neste estudo, entende-se por processos educativos,

[...] processos educativos se desenrolam em práticas sociais, inclusive nas escolares. Os sujeitos que participam de tais práticas interconectam o aprendido em uma prática com o que estão aprendendo em outra, ou seja, o aprendido em casa, na rua, na quadra comunitária do bairro, nos bares, no posto de saúde, em todos os espaços por onde cada um transita, serve como ponto de apoio e referência para novas aprendizagens, inclusive aquelas que a escola visa proporcionar (Oliveira et al. 2009, p.9).

Por seu lado, as práticas sociais são concebidas como:

Práticas sociais decorrem de e geram interações entre os indivíduos e entre eles e os ambientes, natural, social, cultural em que vivem. Desenvolvem-se no interior de grupos, de instituições, com o propósito de produzir bens, transmitir valores, significados, ensinar 
a viver e a controlar o viver, enfim, manter a sobrevivência material e simbólica das sociedades humanas (Oliveira et al. 2009, p.4).

Com base nos conceitos apresentados, nas diferentes práticas sociais existentes no Programa, no convívio entre orientadoras e jovens autores de ato infracional, acontecem processos educativos, nos quais eles se educam uns com os outros. De acordo com Oliveira et al. (2009, p. 6), compreende-se que "As práticas sociais nos encaminham para a criação de nossas identidades. Estão presentes em toda a história da humanidade, inseridas em culturas e se concretizam em relações que estruturam as organizações das sociedades".

Como explicitado neste texto, o conceito de educação é entendido como a formação para a vida, uma vez que se adota a compreensão de educação como processo dialógico, na perspectiva freireana. Assim sendo, abarca um espaço maior que a educação escolar. Nota-se que as práticas sociais advindas das interações estabelecidas em espaços não formais de educação geram processos educativos e esses processos transmitem conhecimentos de distintas formas em diferentes contextos, na maneira de se relacionar com o conhecimento, dele se apropriar e, assim, construir as trajetórias de vida (Freire, 1983b).

Observa-se que os diálogos no Programa de Medidas acontecem entre conhecimentos oriundos da perspectiva de grupos acadêmicos e conhecimentos de vivência de grupos populares. É um trabalho em conjunto para a (re) criação de um mundo mais humanizado, no qual resultam diversas estratégias, (re)significações e intervenções, que desvelam como os sujeitos pensam o mundo e no mundo.

Compreende-se que as educadoras e os(as) jovens, no convívio que acontece no espaço do Programa, se educam na relação entre si, na relação com o mundo e no mundo, por meio da reflexão e da ação, tecendo a realidade enquanto processo de transformação contínua. $\mathrm{Na}$ busca por ampliar a compreensão crítica do mundo o grupo se fortalece como um todo, visto que todos aprendem através das práticas educativas dialógicas, ficando evidenciado que os processos educativos acontecem em diferentes contextos.

Os depoimentos das orientadoras anunciam que as pessoas se educam ao longo da vida, em distintos espaços e momentos, em situações escolarizadas e não escolarizadas, com o objetivo de compreender novas situações e realidades.

A educação vai além da escola, além das matérias... eles se educam aqui, se formam e discutem outros assuntos, que não apenas o da violência (Letícia, 20/03/2012).

Os jovens se educam entre si, [...] podem se unir e levar a uma mudança de postura que são mudanças graduais, que ocorrem no processo (Julia, 14/03/2012). 
Eles já falaram que o Programa é como um amigo, alguém que orienta, acolhe sem julgar. Eles já me perguntaram: "Todo mundo que trabalha aqui é legal?” [...] Já teve meninos que ficaram emocionados na hora de ir embora (Paula, 15/03/2012).

Tudo que ocorre aqui é educativo, [...] a proposta geral é de construção de valores positivos, que auxiliam você a se desenvolver melhor na vida, a essência é essa. Já teve jovem que chegou aqui para as atividades e estava drogado e eu quase apanhei em atendimento. A gente acolhe na hora que eles estão assim, explica que neste espaço não cabe esses comportamentos e agenda para voltar em outro dia, porque tem hora que não dá para negociar, Um dia chegou um menino que tinha usado muita cocaína e a sala tava cheia de jovem, eu tirei ele da sala e levei pro atendimento. Já peguei menino com o nariz cheio de pó... são casos mais graves, mas não todos (Paula, 15/03/2012).

O Programa de Medidas Socioeducativas tem como um de seus focos a civilidade e a ressocialização, onde sejam respeitados os(as) jovens de diferentes classes sociais, raça, cor, etnia e, para tanto, promove ações e reflexão em grupos, que se constituem em processos educativos. O trabalho educativo desenvolvido no Programa de Medidas Socioeducativas está, nessa perspectiva, embasado no conceito de educação, como forma de minimizar o impacto das punições impingidas aos jovens em conflito com a lei, ao longo de suas trajetórias de vida.

Apresenta-se a seguir, alguns excertos das orientadoras em relação ao trabalho educativo que desempenham no Programa:

Eu entendo que tudo aqui no Programa é um espaço educativo, desde ficar na secretaria recebendo e acolhendo o adolescente até os acompanhamentos, enfim nos atendimentos (Paula, 15/03/2012).

Essa mão na massa, de estar junto deles é muito rico, é muito intenso. O grupo é muito rico (Letícia, 20/03/2012).

[...] há uma parceria com o educador, mas também há uma parceria no grupo e tem coisas que surgem no grupo e não aparece no atendimento. Eles falam tanto que às vezes parecem que eles nem sabem que eu estou escutando. E tem coisas importantes que eu troco com as educadoras e isso ajuda nos atendimentos (Fátima, 19/03/2012).

Eu não acho que eu educo, mas as ações são educativas, eu acho que eu oriento. E o que o jovem vai fazer com aquela orientação pode ser educativo ou não. Aqui a gente tem práticas educativas que buscam promover o desenvolvimento integral desses jovens. Aqui 
eu me vejo como educadora social e não como psicóloga. É lógico que a minha profissão ajuda, o olhar clínico contribui, mas não é terapia. $\mathrm{O}$ olhar ampliado contribui para perceber o adolescente para além do ato infracional (Paula, 15/03/2012).

A formação em Terapia Ocupacional dá o suporte para você exercer esse papel de educadora, de orientação. Nas conversas e nos atendimentos, a minha postura é de não ser autoritária e sim tentar refletir sobre o que está acontecendo. A ideia é compartilhar o olhar. Eu levo deles esse ampliar dos conceitos... entendo que o respeitar é conhecer o limite deles, que pode ser anterior. Amplio o olhar sobre qualquer situação problema (Letícia, 20/03/2012).

Toda a organização do Programa anuncia aos(as) jovens e aos seus familiares seu propósito educativo e profissionalizante, com salas e espaços específicos para o desenvolvimento das oficinas, como por exemplo, a sala de informática, a sala para pintura, a quadra para as aulas de futebol, a academia.

Verifica-se que a proposta de trabalho educativo, associada à organização estrutural do espaço do Programa, são ações intencionais, que visam o convívio entre orientadoras e jovens. Tal convívio permite, pela troca entre pares, processos educativos construídos nas relações estabelecidas neste espaço de liberdade vigiada, no qual "esse reconhecimento do outro como sujeito e da ação que ele conduz implica um respeito pelos saberes de experiência" (Oliveira, 2009, p.311).

O convívio pressupõe, portanto, uma variedade de relações entre pessoas e situações, sendo assim compreendido, "Conviver é mergulhar nos processos vivos de educação, saúde, sobrevivência e luta [...]. [...] integrando-o(a) aos movimentos do viver e redirecionando-lhe o olhar para novas perspectivas, visões de mundo" (Oliveira, 2009, p.313). Nesse sentido, a convivência é tida como a capacidade de diálogo harmônico, que advém da união entre as pessoas. Todavia, ao mesmo tempo, traz consigo possibilidade de conflitos, desacordos, rupturas entre pertencentes de um mesmo grupo. "[...] conhecimentos são colocados à disposição e respeitados num processo de conscientização de todos e de ampliação do conhecimento acerca daquela realidade" (Oliveira, 2009, p.311).

As orientadoras relatam o pensar, refletir e o discutir a partir da convivência:

Os jovens me ensinam a olhar para coisas que eu nunca tinha pensado: tabus, valores e olhar a violência de uma outra maneira. Como psicóloga eu entendo que também faço um trabalho educativo e ele acontece por meio do exemplo, um dia eu estava falando para uma menina que ela deveria se vestir 
adequadamente para o trabalho, que trabalhar exigia postura e roupa certa. Mas nesse dia eu estava sem o uniforme daqui do Salesianos... aí eu me perguntei: adianta eu falar isso para ela se eu mesma não estou cumprindo uma regra do meu trabalho? Eu me senti mal. É por isso que eu afirmo que através do exemplo eu ensino muito aos jovens daqui (Julia, 14/03/2012).

Eles me ensinam a respeitar e ficar mais atenta ao outro, como chegar nesse outro... e que cada um é um. A forma de chegar é diferente com um e com outro. Esse respeito em relação ao outro você aprende e amplia essa questão. Aprendi que o que eu acho importante pode não ser tão importante para ele (Letícia, 20/03/2012).

$\mathrm{Eu}$ aprendi com eles a dar valor a minha vida, a minha família. Quando você vê certas situações você reconhece como sua vida é linda e boa (Fátima, 19/03/2012).

O que eles mais me ensinam é que você tem que estar sempre aberta ao que o outro te traz, isso é uma experiência diária, que nenhum caso é igual ao outro por mais que a infração seja a mesma. Cada um é um e você tem que estar aberta para recebê-los, livre de qualquer preconceito. É um exercício diário de ampliar o olhar e se perceber enquanto pessoa e profissional. Eu acho que ensino que aqui é um lugar de troca de experiência, que a gente constrói junto (Alice, 23/03/2012).

$\mathrm{Eu}$ tinha muita pressa para as coisas, hoje eu descobri que tudo tem seu tempo. A mudança é processo e não depende só da gente. E que o afeto é muito importante, faz toda a diferença na vida das pessoas. Essa troca de ensinar e aprender é muito gostosa e a função educativa está em cada detalhe, em cada gesto (Carolina, 16/03/2012).

Ao estabelecer o diálogo com o outro, com a premissa do compromisso ético, aprende-se o 'conviver', o 'estar junto' e a conquista do valioso conhecimento elaborado em comunhão - humaniza-se para humanizar-se, em um processo denominado, respectivamente, educar e educar-se.

O trabalho educativo visa atingir melhorias a todos os jovens que cumprem medidas socioeducativas no Programa, por meio da construção coletiva de novos significados para as suas vivências.

Tem uma frase que eu adoro que diz: "Todo jovem tem um ponto acessível ao bem", basta ao educador conseguir acessar esse ponto. Então aqui a gente acredita no que faz e isso é muito importante (Fátima, 19/03/2012).

Eu não sei se eu educo, mas digo que a gente troca experiências e assim amplia o olhar. A gente constrói junto várias coisas (Alice, 23/03/2012). 
A gente aprende na troca... O educar para mim é além do ensinar... A ideia é tornar o jovem crítico em relação a suas falas. A relação com cada adolescente te soma a ampliar e respeitar (Letícia, 20/03/2012).

Eu gosto de orientar na medida do que eu sei, porque eu sou mais velha e tenho muita experiência de vida. Se eu posso eu me dou mesmo... é o que eu gosto de fazer. Eu já trabalhei com muitas outras coisas, mas na medida em que eu vim pra cá, trabalhar com o social, com os adolescentes... (Fátima, 19/03/2012).

$\mathrm{O}$ vínculo criado entre jovens, educadoras e as ações do Programa fica evidenciado quando muitos jovens que frequentaram o Programa no cumprimento de suas medidas, optam por nele permanecer em alguns cursos, e/ou visitam o espaço com frequência, demonstrando a referência e o vínculo estabelecido com o mesmo.

A orientadora Julia assim declara:

[...] eles voltam aqui constantemente para visitar ou porque estão precisando de uma ajuda em alguma coisa. Essa referência que eles têm do Programa eu vejo como algo positivo, porque eu acho que ninguém busca visitar alguma coisa que lhe tenha feito mal.

[...] adolescentes que vem aqui nos visitar depois de ter passado mais de 10 anos pelo programa. Isso para mim é muito significativo.

A gente encontra na rua, jovens que falam que fizeram a medida e falam felizes, e mandam lembranças... (Julia, 14/03/2012).

Frente aos paradoxos presentes nos espaços de liberdade vigiada e a dificuldade em neles vislumbrar ações educativas, compreende-se que a contribuição social do trabalho é anunciada por Oliveira (2009, p. 313) como “[...] um compromisso com a melhoria das condições de vida e saúde da população brasileira, na busca da equidade, do respeito à vida e da dignidade [...] e da superação de todas as formas de desigualdade e discriminação”.

O trabalho socioeducativo não propõe uma ação pensada e tida como única referencia de verdade. Ao contrário, ela possibilita ao(a) jovem em conflito com a lei descobrir por si mesmo(a), qual o melhor caminho para a garantia da sua qualidade de vida, bem como para a participação social. Nesta perspectiva, podem assumir o controle de suas vidas, por meio da possibilidade de escolhas e (re)inserção social.

Evidencia-se o diálogo com jovens em conflito com a lei, a busca por compreender sua origem e história, o aprendizado de sua realidade social, mediados pela comunicação com compromisso ético, com base na relação dialógica e permitem perceber a realidade e, assim, atuar nela e sobre ela. Trata-se da possibilidade de transformar e (re) 
integrar-se a uma sociedade que acolhe e oferece condições de trabalho e de sobrevivência.

Todavia, apesar da partilha com as pessoas, o aprendizado e a importância do espaço para os(as) jovens, as falas das orientadoras evidenciam também, que algumas situações tornam-se viciosas quando os diálogos e reflexões não atingiram o objetivo de desvelamento da realidade e a mudança de determinados comportamentos.

Eles melhoram, mas muitos continuam infracionando... depende. Uns buscam outros caminhos, mas outros não, eles continuam no ato infracional. Na verdade, teve um menino aqui que ao longo do processo ele melhorou muito [...]. E depois que terminou a medida ele voltou a infracionar, então a gente tenta ajudar, mas às vezes as coisas não deslancham. Falta a questão do suporte contínuo, que a gente não conseguiu fazer ou ele não aderiu a essa rede que poderia dar suporte para além da medida (Letícia, 20/03/2012).

Em relação à questão do suporte contínuo e o princípio da liberdade, Gonçalves e Silva (2003, p. 117) afirmam que "os indivíduos são livres para construir suas identidades, fazer escolhas [...]. Entretanto, nas sociedades multiculturais [...] esse princípio é garantido com rígida separação entre a esfera pública e a privada" (Silva, 2003, p.117). Para além, os autores apontam "[...] imigrantes, negros, minorias étnicas e religiosas, homossexuais, enfim qualquer identidade particular pode exprimir-se como grupo culturalmente diferenciado, desde que o faça em sua vida privada" (Silva, 2003, p.117).

Embora sejam justamente os espaços públicos que deveriam prezar pelo princípio de liberdade, evidencia-se a manutenção da desigualdade entre as pessoas, uma vez que a sociedade nega a heterogeneidade, condenando à margem os(as) detentores(as) de perspectivas multiculturais.

Nessa direção, Dussel (1995) compreende a dominação dos povos latino-americanos como uma dicotomia entre centro e periferia. Opinião hegemônica que, nós latino-americanos, por diversas vezes aceitamos como verdadeira, deixando de lado a nossa identidade, que possui história, contexto social e político e é isso que nos forma. Muitos jovens, em cumprimento de medida socioeducativa, desconhecem sua história, desconhecem suas origens e o que isso significa na construção de sua identidade. Que identidade é essa que eles(as) apresentam? Porque negam a sua origem? E quando negam a sua origem, se apoiam em quais alicerces?

É nesse contexto de construção de experiências culturais que as políticas sociais e, particularmente, as políticas de educação, são postas, muitas vezes, sem o reconhecimento da diversidade e da cidadania. A prática educativa mostra-se aberta no discurso, mas na prática, são descar- 
tadas as características peculiares da cultura, raça, etnia de cada povo. Enquanto educadores(as), comprometidos(as) com a defesa da diversidade, é de nossa responsabilidade elaborar e viabilizar projetos sociais e educacionais tendo como objetivo a melhoria dos processos educativos que ocorrem no interior de Programas Socioeducativos, e que visam a (re)inserção social na esfera pública, como espaço de integração dos indivíduos.

Para tal, há que se compreender o contexto social, político e econômico em que se encontra imersa a América Latina, a fim de que as trocas de vivências e experiências possam favorecer a luta e a conquista dos direitos humanos, da autonomia e das relações igualitárias entre os povos.

Na América Latina, algumas formas de educação formal ou não - podem ser entendidas como resultado de desigualdade econômica e graves conflitos de raça, classe, etnia, de gênero, entre outros. Faz-se necessária a revisão das políticas educacionais e que elas efetivamente se voltem para a qualidade da educação e com o desenvolvimento dos países. Os processos educativos que não respeitam o saber de experiência dos tidos como marginalizados sociais assumem, por sua vez, uma lógica opressiva que desumaniza e impossibilita, ao mesmo tempo, o desvelar de uma consciência crítica. (Freire, 1983a).

Dessa forma, as reflexões propostas neste artigo, sinalizam a relevância do diálogo entre os pares como forma de (re)inserção social de jovens autores de ato infracional, o que permite (re)pensar as relações que ocorrem em espaços não formais de educação, uma vez que se constituí em investimento no âmbito do trabalho educativo e aponta caminho possível para a melhoria da sua qualidade de vida.

\section{ALGUMAS PALAVRAS}

Cabe sublinhar que o estudo apresentado neste artigo buscou analisar uma determinada realidade, com autores(as) e espaços delimitados e singulares, com o intuito de desvelar caminhos, possibilidades e desafios ao trabalho educativo com jovens em conflito com a lei, construindo reflexões e compreensões com as orientadoras acerca dos processos educativos ocorridos no interior de um espaço de restrição de liberdade.

O conviver nesses espaços possibilitou a observação, o diálogo e a escuta atenta, compreendendo o modo de pensar dos profissionais do Programa, suas preocupações, seus anseios e o que os movem no engajamento com seu trabalho, uma vez que conviver com todos(as) trouxe a riqueza de entendimento do trabalho realizado.

É possível afirmar que o Programa é rico e possibilitador de novas oportunidades à vida dos(as) jovens que por ali passam. O que se vê é o aumento da violência em diversos segmentos da sociedade e do tráfico de drogas no país, o que expõe a população jovem, suas famílias e espe- 
cialmente, os territórios vulnerabilizados, a um maior risco de envolvimento com a criminalidade. Frente a tal fenômeno, verifica-se que a sociedade se manifesta com o paradigma da punição, o que resulta em ações de retrocesso diante às próprias leis que garantem direitos a crianças, jovens e adultos, independente de classe social, raça, gênero, em quaisquer espaços onde se encontrem.

Neste cenário, as leis e as conquistas oriundas dos movimentos sociais brasileiros, pela política dos Direitos Humanos e em defesa da proteção integral das crianças e dos(as) jovens, manifestado pelo Estatuto da Criança e do Adolescente (Brasil, 1990) representam marcos importantes, mas ainda a serem consolidados.

Os dados apresentados evidenciam a necessidade de serem consolidadas ações de reversão da cultura punitiva em favor da consolidação de uma cultura socioeducativa. Para tanto, parte-se do pressuposto de que a educação é ferramenta fundamental na construção da concepção de mundo, de forma sistemática pela criança, e que segue permeando todo o seu desenvolvimento.

Os processos educativos propiciados pelas constantes trocas com quem se convive, ambientes familiares, grupos sociais, programa de medida socioeducativa, trabalho, escola, são importantes formas de aprendizado e de práticas educativas, que poderão ser projetadas, aplicadas e/ou avaliadas.

Assim, há que nascer em nós, educadores e educadoras, uma pedagogia da indignação, que se valha da ética humanizadora e libertadora. Nessa perspectiva, entende-se que o presente artigo contribui para que a visão de educação seja ampliada para além do ensino escolar e os processos educativos em instituições não formais de educação sejam destacados, como possíveis espaços para que se busque a formação de jovens em conflito com a lei, bem como se constituem em referências importantes para as pesquisas na área e em possibilidades de formação inicial e continuada de profissionais que atuam em Programas de Medidas Socioeducativas.

\section{REFERÊNCIAS}

BOSI, E. Sugestões para um jovem pesquisador. In: BOSI, E. O tempo vivo da memória: ensaios de psicologia social. São Paulo: Ateliê, 2003, p. 59-67.

BRASIL. Estatuto da Criança e do Adolescente: Lei $\mathrm{n}^{\circ} 8.069$ de 13 de julho de 1990. Dispõe sobre o Estatuto da Criança e do Adolescente e dá outras providências. Brasília, DF: Senado Federal, 1990.

DUSSEL, E. Filosofia da Libertação: crítica à ideologia da exclusão. Tradução Georges I. Massiat. São Paulo: Paulus, 1995 . 
DUSSEL, E. Transmodernidad e interculturalidad (interpretação desde la filosofia de la libertción). México City: UAM, 2005.

FALKEMBACH, E. M. F. Diário de campo: um instrumento de reflexão. Contexto e Educação: Universidade de Ijuí, ano 2, vol 7, p.19-24, jul/set. 1987.

FIORI, E. M. Educação libertadora. In: FIORI, E. M. Textos escolhidos, v. II, Educação e Política. Porto Alegre: L\&PM, 1991, p. $83-95$.

FREIRE, P. Educação como prática da liberdade. Rio de janeiro: Paz e Terra, 1983a.

FREIRE, P. Extensão ou comunicação? Tradução de Rosisca Darcy de Oliveira. Rio de Janeiro: Paz e Terra, $8^{a}$ edição, 1983b.

FREIRE, P. Pedagogia da indignação: cartas pedagógicas e outros escritos. São Paulo: Editora UNESP, 2000.

GONÇALVES, L. A. O. e SILVA, P. B. G. Multiculturalismo e educação: do protesto de rua a propostas e políticas. Educação e Pesquisa. São Paulo, v.29, n. ${ }^{\circ} 1$, p.109-123, jan/jun. 2003.

OLIVEIRA, M. W. Pesquisa e trabalho profissional como espaços e processos de humanização e de comunhão criadora. Cadernos CEDES (impresso), v.29, n. ${ }^{\circ} 79$, p.309321, 2009.

OLIVEIRA, M. W.; SILVA, P. B. G.; GONÇALVES JUNIOR, L.; MONTRONE, A. V. G.; JOLY, I. Z. L. Processos educativos em práticas sociais: reflexões teóricas e metodológicas sobre pesquisa educacional em espaços sociais. Anais da 32a Reunião da ANPED, 2009. Disponível em: http:// www.anped.org.br/reunioes/32a/arquivos/trabalgos/ GTo6-5383--Int.pdf> Acesso em 03/05/2013.

ONOFRE, E. M. C. Educação escolar entre as grades. (Org.). São Carlos: EdUFSCar, 2007.

ONOFRE, E. M. C. Práticas educativas em espaços de privação de liberdade. Revista Educação. PUC-Campinas, n. ${ }^{\circ}$ 27, p.65-74, jul./dez. 2009. 